epiphany

Journal of the Faculty of Arts and Social Sciences International University of Sarajevo

ISSN 1840-3719 / No. 4

Spring 2010

\title{
The Myth of Discovering Absolute Truth through Science: How Szasz Mistook Scientific Evidence for Absolute Truth in An Attempt to Deny the Existence of Mental Illness, and Invalidated Experiences of Those Affected by Mental Disorders
}

\author{
Mirsad Serdarevic \\ International university of Sarajevo
}

\section{Introduction}

There have been numerous advances in the mental health field since Dr. Thomas S. Szasz first expressed his views of mental illness in his seminal work, The Myth of Mental Illness (1961; 1974), almost five decades ago. This work was followed by series of books which reiterated, and in some instances recycled, basic argument made in The Myth of Mental Illness asserting that mental illness does not exist because it is unlike "real" bodily illness. At the core of Szasz's argument is that medical science is a bona fide "science" and all medical specialties, except for psychiatry, follow the rule of "science," because "real" medicine deals with treatment of observable injuries, lesions and other measurable "physicochemical" properties affecting the body whereas psychiatry relies on "psychiatrist's opinion" of so-called 
mental illness. Most debate regarding Szasz's argument has logically focused on the definition of disease or illness (e.g., Kendell, 2004).Szasz has responded to these critiques in his usual selective manner reiterating his well known views while avoiding his critics' legitimate emphasis of recent advances in the mental health field in general and evidence supporting both psychological and biological etiology of mental illness (e.g., Kendell). I propose focusing on validity of Szasz's "absolutist" (e.g., Fulford, 2004; Slovenko, 2004) position which relates "scientific proof" to absolute truth. Interestingly, for someone who holds science in such high regard, Szasz hardly provides any empirical evidence to support his claims. He limits his discussion to the history of psychiatry, hysteria, law, politics, religion, etc. The following is an excerpt from Szasz's writing that shows both his absolutist stance, his assurance that he is "certain" of truth, and an admission of how scientifically unsubstantiated his conclusions are in The Myth of Mental Illness, the article (Szasz, 1960) , and the book The Myth of Mental Illness: Foundations of a Theory of personal Conduct (Szasz, 1961; 1974). "Strictly speaking, then, this paper was not the product of any research. Rather, it was an attempt to tell a truth which, I was certain, everyone knew, but which they were too polite, too timid, too opportunistic, or too uncaring to articulate" (Szasz, 1983, p. 21). Therefore, he was "certain" of a "truth" which "everyone knew," and which was not, as he puts it, "the product of any research." Rather than substantiating his conclusions with scientific evidence, Szasz expects his readers to take his expert opinion on the issue. Szasz expects his readers 
to take his word as the expert and just accept, without the proof of any scientific evidence, that psychiatry is not a scientifically supported branch of medicine. To Szasz, medicine is "scientific" and only bodily illness is "true" illness, whereas psychiatry "invented" so-called mental illness, which is not real and can only be viewed as "metaphorical" illness. In his absolutist stance and dichotomous thinking Szasz misses great deal of the gray area to provide an illusion of objectivity. Noted scholar and professor of religion at Wake Forest University, Charles Kimball writes: "It is much easier to know the truth than to seek it" (Kimball, 2002, p. 68). Unfortunately, Szasz, much like some members of scientific community, often gets carried away and takes the easier route of "knowing the truth," rather than proposing a hypothesis and allowing space for continuous questioning and testing of the hypotheses.

In this article I argue the following points: First, only mathematical proofs are absolute "compared to their poor relation, the scientific proof" (Singh, 1997, p. 23). While Szasz can gather enough data to support his theory or theories, it is unlikely if not impossible that he can prove it through the scientific proof to the "same absolute level of mathematical theorem" (Singh, 1997, p. 23). Second, I provide overwhelming scientific evidence supporting psychotherapy's effectiveness, the discussion of which was omitted in Szasz's The Myth of Psychotherapy $(1978 ; 1988)$ where he compares psychotherapy to "friendship" and even "advertising" (Szasz, 1988, p.3). Szasz bases his critique of psychotherapy on his own personal experiences with psychoanalysis 
and psychiatry of the $40 \mathrm{~s}$ and 50s, generalizing Freud's assertions and psychoanalytic views to all of psychotherapy while neglecting to mention works of Aaron Beck on Cognitive Behavioral Therapy (CBT), Carl R. Rogers, and Viktor E. Frankl, to name a few contributors to the field of psychotherapy, and empirical data on psychotherapy outcome studies showing effectiveness of psychotherapy (g.e., Smith \& Glass, 1977; Wampold, 2000). Third, I summarize Pennington's (2002) arguments to integrate both biological and psychological basis of psychopathology through cognitive neuroscientific theoretical framework. Finally, I would like to acknowledge, Szasz's contributions, despite their limitations, to the mental health field by highlighting the importance of continuous reflection on and critical analysis of our clinical and research practices.

\section{Absolute Proof versus Scientific Proof}

Making a distinction between absolute undisputable proof, or the truth, and a scientific conclusion seems to be crucial in responding to Szasz's arguments about the non-existence of mental illness. To Szasz, scientific proof is synonymous with undisputable truth and only scientifically proven illness is a bona fide "real" or true illness. Szasz, however, seems to have spent most of his energies finding flaws in mental "illness" that he may have overlooked some limitations of scientific proof.

In his wonderfully written non-fiction book, Fermat's Enigma (Singh, 1997), the author, Dr. Simon Singh, a writer with a Ph.D. in physics from the University of 
Cambridge, writes the following about the difference between mathematical and scientific proof: "The difference between scientific and mathematical proof is both subtle and profound..." (Singh, 1997, p. 20). Singh goes on to argue:

Mathematical theorems rely on this logical process and once proven are true until the end of time. Mathematical proofs are absolute. To appreciate the value of such proofs they should be compared with their poor relation, the scientific proof. In science a hypothesis is put forward to explain a physical phenomenon. If observations of the phenomenon compare well with the hypothesis, this becomes evidence in favor of it. Furthermore, the hypothesis should not merely describe a known phenomenon, but predict the results of other phenomena. Experiments may be performed to test the predictive power of the hypothesis, and if it continues to be successful then this is even more evidence to back the hypothesis. Eventually the amount of evidence may be overwhelming and the hypothesis becomes accepted as a scientific theory. However, the scientific theory can never be proved to the same absolute level of a mathematical theorem: It is merely considered highly likely based on the evidence available. So-called scientific proof relies on observation and perception, both of which are fallible and provide only approximations to the truth (Singh, 1997, p. 21).

Singh continues to argue: "Even the most widely accepted scientific 'proofs' always have a small element of doubt in them" (Singh, p. 21). Further, Singh writes: "Science is operated according to the judicial system. A theory is assumed to be true if there is enough evidence to prove it 'beyond all reasonable doubt.' On the other hand, mathematics does not rely on evidence from fallible experimentation, but it is built on infallible logic." (Singh, p. 23). 
Singh uses the problem of the "mutilated chessboard" to demonstrate difference between the scientific approach and the mathematical approach:

We have chessboard with the two opposing corners removed so that there are only 62 squares remaining. Now we take 31 dominoes shaped such that each domino covers exactly two squares. The question is: Is it possible to arrange the 31 dominoes so that they cover all the 62 squares on the chessboard? There are two approaches to the problem: (1) The scientific approach The scientist would try to solve the problem by experimenting, and after trying out a few dozen arrangements would discover that they all fail. Eventually the scientist believes that there is enough evidence to say that the board cannot be covered. However, the scientist can never be sure that this is truly the case because there might be some arrangement that has not been tried that might do the trick. There are millions of different arrangements, and it is possible to explore only a small fraction of them. The conclusion that the task is impossible is a theory based on experiment, but the scientist will have to live with the prospect that one day the theory may be overturned (Singh, 1997, pp. 23-24).

Indeed, scientific empirical articles published in peer-reviewed journals almost always discuss the "limitations" of research methods, measurement errors, etc. due to limitations of every scientific approach. Singh introduces the mathematical approach: 
(2) The mathematical approach

The mathematician tries to answer the question by developing a logical argument that will derive a conclusion that is undoubtedly correct and that will remain unchallenged forever. One such argument is the following:

- The corners that were removed from the chessboard were both white. Therefore, there are now 32 black squares and only 30 squares.

- Each domino covers two neighboring squares, and neighboring squares are always different in color, i.e., one black and one white.

- Therefore, no matter how they are arranged, the first 30 dominos laid on the board must cover 30 white squares and 30 black squares.

- Consequently, this will always leave you with one domino and two black squares remaining.

- But remember, all dominoes cover two neighboring squares and neighboring squares are opposite in color. However, the two squares remaining are the same color and so they cannot both be covered by the one remaining domino. Therefore, covering the board is impossible! (Singh, 1997, pp. 23, 24, 25). 
Singh's illustration of scientific approaches limitations is an important one not only in reviewing Szasz's absolutist stance in articulating his arguments against psychiatry, but also tendency of his critics, as well as other scientists who have throughout history made absolutist claims about their scientific theories. Of course, science has afforded us many privileges and its "approximations" have enabled us to lead healthier and longer lives, among other things, and yet, in our everyday language, we often accept scientific results and scientists' claims as absolute truth. Within scientific circles there is an ongoing debate, if not petty argument, about which field is the most "scientific." For example, physicists and chemists usually consider themselves more scientific than other scientists, and sometimes the two are at argument as well. Biochemists like to mock molecular biologists as "biochemists practicing without a license," while both biochemists and molecular biologists, who engage in "basic science" and explore life at a molecular level, view medical or clinical research as an inferior form of research performed at a superficial level compared to their "real science." Needless to say, social science is often at the bottom of this unofficial hierarchy because natural and physical scientists do not understand how what social scientists do is a science, which is because social scientists encounter numerous challenges such as measurement construction of complex constructs (e.g., measuring emotions, socioeconomic status, etc.) variables other scientists do not have to consider. It is only ironic that mathematicians are often left out of this discussion, given that they are the only ones who can make 
claims of absolutely "proving" something. It is given that mathematics is given its credit, but it seems often in passing, something taken for granted by other scientists who used it in applied way, and view it from a utilitarian perspective. Ironically, despite competitiveness among science fields, the path of science has led to integration of different fields rather than differentiation. Fields such as biophysics, biochemistry, psychobiology, cognitive neurosciences, social medicine, preventive medicine, anthropological medicine, health psychology, etc. have emerged significantly contributing to recent scientific discourse. Indeed, integration of different branches of science seems appropriate for the study of such complex problems as mental illness, among other problems in physical, natural and social science which require integrative formulation for understanding of complex phenomena.

\section{The Reality of Psychotherapy}

As mentioned earlier in this article, Szasz tends to generalize his training in and understanding of psychoanalysis to all of psychotherapy. In The Myth of Psychotherapy Szasz is so certain of what psychotherapy is that he likens it to something "comparable to friendship" and "advertizing" (Szasz, 1988, p.3). Again, he sounds convincing in that he comments on what I believe was reality of his psychoanalytic training in Chicago in the 1940s and the state of psychiatry in the early 1950s, but there is nothing objective or scientific about his personal 
observations. The following are just few arguments demonstrating evidence of psychotherapeutic effectiveness Szasz conveniently neglected to mention in The Myth of Psychotherapy.

Smith and Glass (1977) performed the first meta-analysis of psychotherapeutic treatment outcomes. In their meta-analysis Smith and Glass reviewed all 375 studies comparing psychotherapeutic treatment to a control group. Smith and Glass provided evidence supporting the claim that psychotherapeutic treatment is effective form of treatment for mental illness. More importatantly, they showed that some components common to all therapies, rather than one specific to one psychotherapeutic modality, made psychotherapy effective. Examples of common components are the healing context and the meaning attributed to it by both the patient and the therapist, as well as the delivery of therapeutic "interventions" consistent with the rationale for therapy (Frank and Frank, 1991). Frank and Frank go on to propose that the client is mobilized and motivated in such a healing context and expects to improve, which leads to development of a therapeutic relationship. Wampold (2000) argues that, when taken as a system that is shared across psychotherapies, evidence supports components and contextual processes as effective and efficacious therapy for mental illness. It is important to note that Smith and Glass (1977) were followed up by other meta-analytic studies all of which indicated effectiveness of psychotherapy and provided evidence for common factors (Wampold, 2000). 
Frank and Frank (1991) write the following (which I suspect was not part of Szasz's psychoanalytic training in the 1940s) about psychotherapy: "Therapists should select for each patient the therapy that accords, or can be brought to accord with the patient's personal characteristics and view of the problem" (Frank and Frank, 1991, p. xv). We now know that there is no such thing as a "value neutral" science, including psychology (Prilleltensky, 1989) and that patients cannot be viewed as apolitical, acultural, ahistorical, acontextual beings (Marti-Baro, 1994) living in a vacuum, which is how they were treated in traditional psychoanalysis, where only context considered, to a limited degree, was family, but other environmental factors were neglected if not ignored altogether. From this perspective Szasz is right to pick on Freud and psychoanalysis, but he does not stop there and goes on for a full on assault on psychotherapy, a subject which he thinks "knows," I suppose because it is easier to "know" and reduce the entire field to something like "advertisement" than to "seek" the truth and explore this complex activity from a scientific perspective.

Lott (2002) talks about "cognitive distancing from the poor" that has extended from the general society into sciences, including psychology, which neglect the poor and influence of poverty on physical and mental well being. Szasz provides good example of this in The Myth of Mental Illness: Foundations of a Theory of personal Conduct (Szasz, 1961; 1974) where he goes beyond ignoring the poor, but is quick to argue that physicians have no role in helping the poor. At the very least one can 
observe the link between poverty and malnutrition (if not on mental health), one of the reasons why we have preventive medicine and public health, so it would seem to me that poverty is very much so within medicine's jurisdiction, in addition to other governmental agencies' jurisdiction. I am not proposing that Szasz is not empathic or does not have compassion, because he is certainly passionate about rights of patients and rightly objects involuntary hospitalization, both surely humane goals, but misleading when looking at the bigger picture of his proposal.

Basically, Szasz is big on liberty and individual rights, but ignores oppressive elements of society and their effects on human physical and mental health. For example, it has been shown that gender and racial discrimination is associated with hypertension (e.g., Krieger, 1990), perceived discrimination with depression (e.g., Noh \& Kaspar, 2003), and that there is association between stressful environment and changes to corticoids levels (e.g., Pennington, 2002), and yet Szasz invalidates experiences of the oppressed and existence of mental illness. He does so from the point of privilege: able-bodied, White male, of upper-middle socioeconomic status (SES) and of aristocratic background. From this perspective it is easy to see how Szasz would emphasize personal responsibility and minimize oppressive elements present in all societies.

To complicate matters Szasz can make a point of the fact he overcame a lot as an immigrant who at 19 years of age had to uproot and adjust to new language, 
society and culture, which may have given him a sense of shared experience with other oppressed groups. However, I propose that those "shared experiences" are only superficial, and there is a profound difference between someone who is immigrating to a new society, granted faced with many challenges, but from privileged background and speaking multiple languages, and someone who was born in poverty, was malnourished, discriminated against, never knew anyone with more than high school education and received subpar education herself. I do not propose that I can even begin to understand, beyond intellectual knowledge, of what it feels like to be, for instance, discriminated against on a daily basis. This is why we ought to be careful when we talk about personal responsibility and what "others" should and should not be doing. Personal responsibility is certainly important and empowering for any individual, but it is a bi-directional, dynamic exchange between the individual, who has some abilities to exert power on her environment, and her environment (Bronfenbrenner, 1989) which can be supportive and facilitate individual growth or oppressive and lead to maladjustment. It would be challenging to work with those who have, as Szasz calls it "so-called mental illness" if you cannot recognize oppressive nature of peoples developmental contexts, it is virtually impossible to do psychotherapy if one does not give these contextual factors their due. 


\section{The Gray Area "and" the Gray Matter: An Argument for Integration of the}

\section{Biological and the Psychological}

Pennington (2002) highlights lack of integration between psychological and physiological theories in the extant mental health literature. Pennington argues for integration of the biological and psychological mechanisms implicated in developmental psychopathologies. Further, Pennington argues that biological and psychological explanations of the same clinical phenomenon (e.g., depression) are "not necessarily competing explanations" (Pennington, 2002, p. 3). Biological and psychological approaches "may be complementary, each operating at a different level of analysis" (Pennington, 2002, p. 3). Pennington goes on to argue:

However, for either the biologist or the psychologist to think about how these two explanations relate to each other is not straightforward because a theoretical framework for integrating these different levels of explanation is only beginning to emerge. This neuroscientific framework seeks to relate behavior and mind to the brain. It is important to realize that every psychopathology requires us to solve the brain-behavior or mind-body problem. It is not enough to frame an explanation of a psychopathology purely in terms of mental or psychological constructs. To do so ignores the brain. At the same time, to frame an explanation purely in terms of brain variables such as receptor efficiencies or densities is not enough. To do so reveals a naïve reductionism, because even if the causal brain variables were known, we would still need to know how these brain differences lead to changes in behavior. (Pennington, 2002, p.3) 
Pennington concludes that the point of a neuroscientific perspective is that all social influences affect brain development while brain mechanisms implement all psychological constructs. Illustrating brain-behavior or mind-body connection Pennington discusses how traumatic social experiences such as abuse or neglect “can cause very persistent changes in brain development" (Pennington, 2002, p. 4). Pennington's proposed model of causation is presented in Figure 1.

Figure 1. Proposed bidirectional model of causation: (A) Etiology -> (B) Brain development -> (B)Neuropsychology -> (C) Behavior Note. Where behavior then has a bidirectional effect on both original etiology and brain development (i.e., there is a feedback loop with an arrow back from behavior towards both etiology and brain development). Environmental strain (e.g. the war zone) -> (B) Neuropsychology (biochemical changes in the brain due to emotional and cognitive strain)-> (C) Behavior(s) (diagnoses PTSD).

Consider the following hypothetical, though currently possibly real scenario for Troops: The soldier who is under daily stress, and is patrolling the streets, surrounded with many ordinary, harmless people, but he understands that at any moment someone may emerge from the crowd with an explosive and kill him, his comrades, and many civilians he is trying to protect. In fact, this soldier is very tense because, in addition to his already dangerous mission of keeping peace in crowded streets, where 
everyone can be potential enemy, he witnessed death of his close friend just weeks ago. Moments feel like hours and hours feel like days. He has been doing this for weeks now. He is hyper-vigilant and he's feeling fatigue, both physical and mental, he has difficulty falling asleep at night. He survives his tour and he comes home to be diagnosed with a Post-Traumatic Stress Disorder (PTSD). In this example we can think of his environment comparable to that of a weapon, let us say a pistol, except instead of a flesh wound, days in the field have put an extreme mental pressure, which has changed biochemistry of his brain, causing him to have numerous sleepless nights, nightmares, low mood, and sudden bursts of aggression. His new "behaviors" are now disrupting his attempts at re-establishing his old life with his family. A simplistic representation (see Figure 1) of this example is consistent with cognitive neuroscientific approach.

According to Szasz, there is no mental illness. Rather, it is really "life" that happened to to people affected with it (e.g., the soldier in the above example), they had "tricked" themselves into believing that they are fine going about life as they were (e.g., performing duties as a soldier) and should be "responsible" for their choices, deal with consequences of those choices and accept all discomforts that they may feel, because they certainly cannot have mental illness because it does not exist, as Szasz has stated so many times. Szasz may also suggest that the soldier in the above mentioned example may be malingering, and just hoping to get financial or health benefits from the VA. Szasz often talks about dehumanization of psychiatry, 
but, if his previous arguments would indeed translate into this kind of an interpretation of the situation, I am not sure if it is only psychiatry that is dehumanizing.

\section{Conclusion}

To reiterate Kimball's words (2002), it is much easier to "know" the truth than to "seek" it. Szasz, ironically much like Freud and other authoritative psychiatrists whom he criticizes, seems to have taken the easier road in his absolutist stance as a psychiatric abolitionist, a stance and view which remained practically unchanged over several decades. To be fair to Szasz he uncovered some harsh realities of psychiatry of his time, and was ostracized by the psychiatric establishment, which could not have been easy and is still probably difficult. Still, to reiterate his words about his original article, The Myth of Mental Illness, published in the American Psychologist: "Strictly speaking, then, this paper was not the product of any research. Rather, it was an attempt to tell a truth which, I was certain, everyone knew, but which they were too polite, too timid, too opportunistic, or too uncaring to articulate" (Szasz, 1983, p. 21). Well, at least he is candid. So, Szasz used "science" to challenge the concept of mental illness and discredit psychiatry as a bona fide science, but he published his seminal article deplete of "any research," simply because he "was certain," and expected us to take his word for it. As I discussed in the first part of this article even if Szasz provided some scientific evidence, because 
of the nature of "scientific proof" and its limitations, he could still not prove his claims to the absolute level which would justify his absolutist stance.

It is challenging, if not agonizing, to criticize Szasz. He sends consistently contradictory messages of liberty, individual rights, poor psychiatric and mental health facilities, and banishment of involuntary hospitalization, all noble causes as we may agree. Yet, Szasz is very punitive toward an individual who goes even a little astray, discounting oppressive environment which may have contributed to it, as he highlights personal responsibility and unquestionably supports the rule of law (as if legal codification is naturally occurring law, ultimate guide and not an artificial codification which has been evolving for years. Than there is something very peculiar: Szasz proposes that the "mentally ill" should fight for their rights, as other oppressed groups have throughout history (Szasz, 1963; 1989, p. 253). So, Szasz is telling a group of mentally ill persons, whose condition he ceases to acknowledge or validate, to fight for their rights? He invalidated experiences of so many and reduced it to problems of life, and therefore implied that somehow they are deficient in coping mechanisms that others, perhaps like himself, may have. He also acknowledges that there is something to the whole idea of "mental illness" when he is calling for "the mental patient's liberty" (Szasz, 1989, p. 253). He then identifies, yet one more time, psychiatry as "oppressor," concealing bigger societal oppressors. Perhaps, if we lived in a more just, less oppressive systems, there indeed would be 
less need for mental health services, including psychiatry, but I would propose that, at least to a degree, all mental health services including psychiatry, psychology, counseling, social work, etc. are necessary bandages in the oppressive society where trauma happens on all levels of social ecology (i.e., family, neighborhood, larger societal levels such as xenophobia often infused in general culture of the dominant culture as well as in numerous policies, etc.). To say that there is no mental illness is to invalidate residual effects of horrible traumas such as rape, sexual and physical abuse, domestic violence, horrors of war, all of which can lead to numerous disorders such as PTSD and many personality disorders. If it is an issue of semantics and Szasz does not want to label persons as "ill" that would be perfectly fine in the society which would allow everyone to still receive needed care in some sort of humanitarian institutions with unlimited resources, but in present societies, to take away this label, is to leave person out on the cold. Persons may suffer, but because they suffer from nothing or "problems of life," as Szasz would argue, they would not receive any care. The label, however imperfect, and often misused, is also a form of protection. Szasz does not see it this way and his attitude often is malingerer until proven otherwise, but since there is no mental illness than they all must be malingerers looking for primary or secondary gains, or perhaps a benefit from the VA. 
To "destroy" psychiatry, as Szasz suggests (Szasz, 2004), and take his suggestions for the alternative, which would include boutique style of resorts, which would not resemble hospital nor hotel, but be some kind of a hybrid institution, would mean that only very wealthy could receive "treatment," and all others would either have to cope with their "so-called mental illness" or would end up in prison. That is not all, however, Szasz does think that people should have a right to take any drug they want or take their own life, so one cannot accuse him of not providing alternatives.

Despite their demonstrated shortcomings, Szasz's contributions to the mental health field are indeed valuable and highlight the importance of continuous reflection and critical analysis of our clinical and research practices.

It is difficult to "destroy" anything, much less a multidisciplinary field serving millions of persons afflicted with disorders that may not be observable as "lesions" (but than again numerous other diseases now readily accepted as a bona fide diseases, based on Szasz's criteria, wouldn't have met the criteria few decades ago), but are just as real and cause true suffering. To deny existence of mental illness is to invalidate experiences of persons afflicted with it. Psychologists, psychiatrists, physicians, social workers have both moral and professional responsibility to advocate for the poor, oppressed and disenfranchised in an attempt to make a more 
just society. We could think of this duty as not only a preventive measure, but a humane one. 


\section{References}

Bronfenbrenner, U. (1989) Ecological systems theory. Annals of Child Development 6 187-249.

Frank, J. D., \& Frank, J. B. (1991) Persuasion and Healing: A comparative study of psychotherapy (3rd edition). Baltimore, MD: Johns Hopkins University Press.

Fulford, K. W. M. (2004) Values-based medicine: Thomas Szasz's legacy to TwentyFirst Centrury psychiatry. In: J. A. Schaler (Ed) Szasz Under Fire: Psychiatric abolitionist faces his critics. Chicago and La Salle, Illinois: Open Court.

Kendell, R. E. (2004) The myth of mental illness. In: J. A. Schaler (Ed) Szasz Under Fire: Psychiatric abolitionist faces his critics. Chicago and La Salle, Illinois: Open Court.

Kimball, C. (2002) When Religion Becomes Evil: Five warning signs. New York, NY: HarperCollins $\quad$ Publishers, Inc. Krieger, N. (1990) Racial and gender discrimination: Risk factors for high blood pressure? Social Science and Medicine 30 1273-1281.

Noh, S., \& Kaspar, V. (2003) Perceived discrimination and depression:

Moderating effects of coping, acculturation, and ethnic support. American Journal of Public Health 93 232-238. 
Pennington, B. F. (2002) The Development of Psychopathology: Nature and nurture. New York, NY: The $\quad$ Guilford Percival, R. S. (2004). Persons and Popper's Worlds: Do Humans Dream of Abstract Dreams. In: J. A. Schaler (Ed) Szasz Under Fire: Psychiatric abolitionist faces his critics. Chicago and La Salle, Illinois: Open Court.

Singh, S. (1997) Fermat's Enigma. New York, NY: An Anchor Book Doubleday. Smith, M. L., \& Glass, G. V. (1977) Meta-analysis of psychotherapy outcome studies. $\begin{array}{llll}\text { American } & \text { Psychologist } & 32 & 752-760 .\end{array}$ Slovenko, R. (2004) On Thomas Szasz, The meaning of mental illness, and the therapeutic state: A critique. In: J. A. Schaler (Ed) Szasz Under Fire: Psychiatric abolitionist faces his critics. Chicago and La Salle, Illinois: Open Court.

Szasz, T. S. (1960) The myth of mental Illness. American Psychologist 15 113-118. Szasz, T. S. (1961) The Myth of Mental Illness: Foundations of a theory of personal $\begin{array}{llll}\text { conduct. New } & \text { York, } & \text { NY: } & \text { Hoeber-Harper. }\end{array}$ Szasz, T. S. (1974) The Myth of Mental Illness: Foundations of a theory of personal conduct (Revised Edition). New York, NY: HarperCollins Publishers, Inc. Szasz, T. S. (1988) The Myth of Psychotherapy. Syracuse, NY: Syracuse University Press.

Szasz, T. S. (1983) This Weeks's Citation Classic. Current Contents 4421. $\begin{array}{lllll}\text { Retreived on } & \text { August } & \text { 12, } & \end{array}$ 
http://www.garfield.library.upenn.edu/classics1983/A1983RM10400002.pdf

Szasz, T. S. (2004) Reply to Kendell. In: J. A. Schaler (Ed) Szasz Under Fire: Psychiatric abolitionist faces his critics. Chicago and La Salle, Illinois: Open Court.

Szasz, T. S. (2004) Reply to Fulford. In: J. A. Schaler (Ed) Szasz Under Fire: Psychiatric abolitionist faces his critics. Chicago and La Salle, Illinois: Open Court.

Szasz, T. S. (2004) Reply to Slovenko. In: J. A. Schaler (Ed) Szasz Under Fire: Psychiatric abolitionist faces his critics. Chicago and La Salle, Illinois: Open Court.

Szasz, T. S. (2004) Reply to Percival. In: J. A. Schaler (Ed) Szasz Under Fire: Psychiatric abolitionist faces his critics. Chicago and La Salle, Illinois: Open Court.

Szasz, T. S. (2007) The Medicalization of everyday life: Selected essays. Syracuse, NY: Syracuse University Press.

Wampold, B. E. (2000). Outcomes of individual counseling and psychotherapy: Empirical evidence addressing two fundamental questions. In: S. D. Brown and R. W. Lent (Eds) Handbook of Counseling Psychology. New York: John Wiley. 